\title{
SOME PREVALENT FALLACIES IN VITAL STATISTICS.
}

\author{
Bx EDWARD F. WILLOUGHBr, M.D.Lond., D.P.H. \\ Lond. \& Camb. Univs.
}

(Meniber.)

Read at Sessional Meeting, December 1.,th, 1598.

WE are often told that "statistics may be made to prove anytling," and so, like balance sheets, they may, and too of ten when ignorantly or frauclulently manipulated indeed; this remark, so flippantly uttered by indolence, incredulity, or inlifference expresses a great trutl, especially in respect of l)emography, or Vital Statistics, the science on which all social legislation, sanitary improvement, and philanthropic effort must be based, for without figures we can prove nothing, and public action prompted by popular notions or inclividual experience is always hazardous.

Vital and social statistics have been aptly compared by Dr. Longstaff to "indeterminate equations, with many unknown quantities, of which approximate solutions only are possible." The qualifications of the statist are not those of the accountant or the actuary, he need not be versed in the higher mathematics, but he must hare a naturally logical mind, triined in the methods of scientific inference, inductive and deductive, combined with a comprehensive knowlerlge of the subject under consideration, the various sources of fallacy incident thereto, and the disturbing influences to which its phenomena are exposed; for the conditions of several communities being rarely, if ever, even approxinately the same in all or in most respects, crude recorded facts are always fallacious, and apparently obvious conclusions drawn therefirom seldon correct; the truth lying beneath, of ten very far beneath the surface, and requiring for its discovery all the slitl of the practised expert.

Thus the most rapidly increasing populations may be fast tending to extinction; the healthier may show the higher deatl-rates; short-lived communities may boast the largest proportion of aged persons; the mean age at death may be low in the healthiest occupations, and deaths at advanced ages be no evidence of conditions favourable to health and longevity ; 
the natural increase of the entire population of a country may be accelerated or retareled at will without any change in the proportion of women marrying or the number of children to a marriage, the gencral mortality, or the extent of emigration; and, incredible though it may appear, it is possible that the very improvement in the sanitary conditions of the people now in progress, coupled with the falling birth-late, may lave for one of its consequences in the earlier half of the coming century a considerable rise in the annual death-rate which shall not indicate any deterioration of the public health. These paradoxes are all easily explained and are then pregnant with instruction; but it is rare to meet with a report on the sanitary conditions of a town, or the healthiness or unhealthiness of an occupation which is not more or less falsified by ignorance or neglect of the methods of correction.

It is impossible for me in the limited time allowed on this occasion to toucl on the fallacies incident to all popular discussions of such social and economic problems as those of the so-called depopulation of the rural districts, and the migration to the towns, the distribution of wealth, and the growth or decline of pauperism, over-population, emigration, and other industrial questions in their relations to demography, and I must confine myself to pointing out a few of the most frequent and gravest mistakes arising from the abuse of statjstics.

Estimated populations, based on the assumption that the rate of increase observed in the last decemnium is maintained in the present, lead to serious errors in the calculation of the death-rate and the presumed healthiness of the community, for if the estimated differ from the actual population by no more than 10 per cent. plus or minus, a supposed death-rate of 24 per 1000 will represent a true rate of 26.4 or 21.6 respectively, and each successive census effects rude disillusions. Thus, in 1871 the population of Gosport was found to have been overestimated by 33 per cent, and that of Cambrilge under-estimated by 16 per cent., their death-rates being identical instead of differing by 12 per cent. In 1881 that of Kensington had been over-estimated by 26 per cent., and its vaunted death-rate of 15 per 1000 was turned into the very ordinary 18.75 .

In 1891 the population of London was found to be, as Dr. Longstaff had predicted, a quarter of a million less than the Register General's estimate; the increase in the decennia $1 \times 71-\$ 1$ and $1881-91$ has fallen almost everywhere, iu Nottingham from $34 \cdot 3$ to $13 \cdot 6$ per cent., in Hull from $26 \cdot 5$ to $10 \cdot 9$, in Salford from $41 \cdot 2$ to $12 \cdot 4$ and in Liverpool from 12 to decrease of $(j \cdot 2$; the deatlis in fact had always been in excess of the births, the apparent growth of population being merely 
the consequence of immigration, and ceasing as soon as this received a check. All the death rates had been understated, that of Salford as $3: 4$ !

Constitution of populution.-Since the end of the determination of the death-rate is to ascertain the accidental conditions, sanitary, social, or inclustrial, affecting the health of the people, it is necessary that rlifferences in the essential conditions, which are not under our control, but none the less exert an influence on the cleath-rate, irrespective of those that are remediable, should be eliminated before any conclusions are drawn ; or as logicians express it, that all the phenomena should be common except those which constitute the causes or the effects of the phenomenon that is the subject of enquiry. Foremost among these is the age and sex constitution of a population. Since the death-rate of children under 5 years is 63 per 1000 , of persons from 5 to 25 only 6 per 1000 , and of those from 25 to 45 years of agre 10 per 1000 , it is eviclent that a preponderance of individuals of one or other of these age periouls will wreatly influence the cleathrate even should all other conditions be identical; and conversely that if the age constitutions be the same, the influence of those remediable conditions that determine an excessive mortality will be seen in the cleath-rate. The decennial reports of the Registrar General enable us thus to reduce the popnlations of every town or district to a common standard, thereby rendering them comparable. He publishes the number's of persons of each sex and within each age period, together with the death-rate for each sex and age for the country as a whole, and the sex and age constitution of the population of each town separately. From these datil one is able to calculate for any place two death-rates besides the crude or "recorded" rate, viz., the "standard rate," or that at which, constituted as they are, they ought to die if the conditions under which they lived were no better or worse than those of the country generally; and the "correcteri rate," or that at which under existing conditions, they would die if only the relative proportions of persons at each age period did not differ from those of the nation taken as a whole. The standard represents a rate presumably attinable in the present state of civilization, and therefore to be aimed at; the corrected rate exhibits the naked truth, stripped of the accidents by which it was concealed.

One example, that of Manchester, will suffice to explain the meaning of these rates. In 1891 the crucle or recorded deathrate was $28 \cdot 67$, the standard $19 \cdot 09$, and the corrected $31 \cdot 95$; the extremes of 32 and 19 representing the actuil state of the population and what it might be with no better condition than those of England generally, and the difference $12.5 \mathrm{per}$ 
thousand, or 40 per cent. of the total mortality, indicates the amount that is preventable. Crucle death-rates are determined far less by the sanitary conditions than by the ages of the people, and the aim of "correction" is to cxclude this source of error. But there is in many towns a disturbing factor that cannot be eliminated, yet has not received the attention it deserves. I mean the presence of a large number of female servants, who, like all young unmaried women, tend to lower both the birth and death-rates but, unlike others, may be said never to clie at all, for if they seem likely to do so they are at once sent to their homes mostly out of the district, and their places are filled by others from elsewhere. Their influence on the death-rate is therefore the same as would be exerted by the presence of a like number of immortals, and is greatest where there is no considerable working class population from which they might be drawn. Great public schools, universities and garrisons act in like manner, but are not so apt to be overlooked.

The mean age at death is of little practical value since the same mean may be obtained from very different extremes, as a ligh death-rate in early life with longevity among the survirors, and a low infant mortality with few cases of extreme longevity, the majority reaching a good age.

Better far is the mean lifetime of a population as deduced from life tables, or the age at which a generation, e.g., 100,000 born, is reduced to half.

The mean duration of life obtained by dividing the population by the mean annual number of deaths is a fertile source of error. Thus, if 100 deaths occur annually in a population of 4,000 , that is one person in 40 dies every year, the death-rate is 25 per $1,0(0)$, and the mean duration of life said to be 40 years. This, however, is true of a stationary population only, one in which the births equal the deaths, as in France, but most misleading where for two removed by death three are introduced by birth or immigration, so much so that with the highest birth-rate possible under the circumstances, the deatli-rate of 5 per 1,100 assumed by Sir B. W. Richardson for his Hygeiopolis might imply a mean lifetime, not of 200 years, as was hastily asserted, but of one little over the traditional threescore years and ten.

The expressions "excess of birtlıs over deaths" and "high and low (general) death-rates," though convenient and, in the absence of better, indispensable, are as Prof. Ruata, of Perugia, points out, inaccurate and liable to misapprehension. Since each event happens once and but once to all men, they must be equal in the end to the number of persons who have lived. The apparent excess of births is due to the increase in geome- 
trical progression of actively reproductive individuals in the community; and by a high death-rate we mean an undue proportion of premature and avoidable deaths, in the reduction of which preventive medicine has achieved its greatest triumphs; e.g., of a million children born 25,000 more reach the age of 15 , and 40,000 more that of 30 , than in the last generation. Between 1860 and 1890 the mortality from scarlatina sank from 0.983 to 0.246 per 1000 , or as $4: 1$; from enteric fever from 0.850 to $0 \cdot 180$, or nearly $5: 1$; and from phthisis from $2 \cdot 528$ to 1.635 , or $3: 2$. Yet the waste of infint life is still appalling, 18 or 20 of 100 born dying in the great manufacturing towns, and 15 in England generally in their first year against 9 or 10 in Ireland and in Norway. But since everyone will die sooner or later, a reduction of the deaths in one arreperiod must be compensated by an increase in another, and the consummation of preventive medicine would be attained when the whole mortality should be concentrated in the last decade of human life. Already the mean lifetime las been extended by four or five years, but fewer I believe attain to extreme old age than formerly. Patriarchal longevity requires patriarchal conditions and habits, and centenarians caunot be numerous in the present strain and struggle of life. But

\section{"Better fifty years of Europe Than a cycle of Cathay,"}

and our end will have been achiered when nearly all shall survive far into the period of useful activity, and those who reach a good old age shall retain their faculties and energies to the last days of their lives, senile decrepitude and imbecility being no longer known.

The deaths of infants, of children under 5 , and of persons over 60 , if they are to be of smallest use, should never be calculated on the total population, or on the deaths at all ages, but on the number of persons living at that particular age, or in the case of infants uncler one year on that of the births in the year, and on it their mortality must always be calculated; but as to the others, unless the numbers living be known at least approximately, their special death-rates should be ignored.

The proportion which the number of old people bears to the total population is no indication of the general longevity, this factor being deternined far more by the fertility of the marriages; thus if in three communities the average number of children to a marriage be three, four, and six respectively, supposing all adults to marry and making no allowance for deaths, the grand-parents in the third generation will be to their descendents as 1 to 5,7 , and 13 . It is in this way that the French 
lave been erroneously credited with a greater general longevity than the English, solely on account of their smaller families.

Two examples of discises incident to different periods of life will suffice to show the importance of taking into account the age-constitutions of communities in comparing either the absolute or the percentuge mortalities from any particular cause; and this whether the differences in constitution be the results of higher and Jower birth-rates, expectation of life, or of migration.

Scarlatina is, as all know, a disease of early life, more than 10) per cent. of the deaths being among children under 10 years of age. Now these form $25 \mathrm{per}$ cent. of the population in London and Berlin, but only 12.4 per cent. of that of Paris. Equal death-rates from scarlatina would therefore imply a mortality in the French capital really twice as high as in the English and German, and the actual numbers per 1000 of the total population being $3 \cdot 4$ and $2 \cdot 8$, it follows that among like numbers of children, to 10 English or German no fewer than 23 French children die from this cause. Again, cancer is essentially a disease of advancing age, scarcely known among those who have not passed whit Dante called il mez o del cammin di nostra vitu, or their 35th year, and nearly three times as fatal in the second as in the first of the decennia following; the natural result of an increase of proportion of individuals over $40 \mathrm{or} 45$ years of age, whether brought about by a reduction of the number of premature and preventable leaths, and consequent saving of life in the most active and productive period, which is the greatest success as yet attained by preventive and curative medicine, or by a falling birth-rate, which may be an indication of good or ill omen, according as it is prompted by proper prudence or by selfish motives and immoral habits - the natural result, I say, of such a change in the age-constitution of a population would be a great and progressive increase in the number of deaths, and in the deatllrate for all agres from cancer, even though the incidence were no greater and the case mortality less.

The natural increase of a population depends not only on the number and fertility of the marriages, but on the age at which girls are married, for while it is doubtful whether, within certain limits, this makes much difference in the number of children to a marriage, it is clear that the rate of increase of the population will be influenced by the intervals between successive generations; thus if the average age at which the girls marry be 19 , there will be 5 , and if 24 , then only 4 to a century, and the population will increase in like proportions, though all other conditions and factors be the same, recourse to artificial means for the limitation of families being uncalled for. If on 
the other hand there is a great demand for population there is always a large reserve of marriagcable and eligible persons of both sexes to be drawn on even to the extent of doubling the birtlrate.

In determining the furtility of women or the number of children to a family, the births should be calculated not on the number of marriages, but of women who have married, for the procreative period of the female being limited, a widow who marries again does not make a fresh start, but is in the same position, if still young, as she would have been had her first husband not died, and if old as if she had remained a widow.

More women than men marry, for second and third marriages are more frequent among men, and while widowers often marry spinsters, bachelors rarely marry willows.

The correspondence between the oscillations of the marriage and birth-rates is remarkable, considering that women once married continue to bear clildren for ten or more years, but I think that the explanation is to be found in the fact that while of married women in general one only in three or four gives birth to a child in each ycar, at least haif of the newly married do so in the first year or two after marriage. We may compare with this the enormons rise of the birth-rate in Germany in the year following the Franco-German war, when ncarly a million young men were drafted into civil life, and over half a million married men returned home to their wives in robust health after one or two year's' separation.

The comparative healthiness of occupations is a question bristling with fallacies, and one respecting which extraordinary misconceptions prevail. There is no denying that, though individuals may be found enjoying good health and attaining old age under the most unfivourable conditions, many occupations are more or less unhealthy and tend to produce disease and premature decay. But the common practice of taling the mean age at death as an indication of the healthiness of an employment is delusive in the extreme, for in all classes of society there are some that for various reasons, as the bodily strength or mental activity required, or the remuneration given are followed by the young only, who in later life turn to other occupations; some positions to which men attain only after a long preparation, and others again for which elderly men of tried honesty and sobriety are preferred. No doubt the circumstances and mode of life of some professions and occupations are highly conducive to health and longevity, while those of others are unaroidably the reverse. But other factors must not be lost sight of. The longevity of bishops and judges is well known and that of pensioners is proverbial, but the

rox. Xx. Pant I. 
former are men who, haring reached or passed middle life, are still vigorous in mind and body, and the latter, after long years of regular and industrious lubits, enjoy freedom from further care and worry. Such men cannot dic young, for there are no young men among them, and to say that judges, bishops, and generals attain greater ages than barristers, clergymen, and inferior officers, is merely to say that old men live longer than those who die young. It is puerile to infer, as Dr. Rohé does, the healthiness of their occupations from the mean age at death of sailors and of lighthouse kecpers, of professors and of students, of merchants and of clerks, or to say that telegraph clerks and soldiers die mostly between twenty and thirty. The only proper methoul is that of Dr. Ogle, viz., to compare the deathrate per thousand living with that of the general population of the same age and sex.

Then there is the question of selection, the physical qualifications required determining to a great extent the choice of an employment, for only sturdy lads can be ilprenticed as smiths or shipwrights, while the weakly must be put to tailoring or sloemaking; only sober men are accepted as engine drivers or railway guards, but anyone can be a cabman.

$A$ like fallacy is involved in the assumption that married life is in itsclf more conducive to health and longerity than is celibacy. No doubt bachelors are more prone to irregular habits, but many persons of both sexes abstain from marriage on account of their ill health or plirsical defects, and are not unhealthy lurense they remain single. The influence of the marriage market on female labour and employment is such as to deprive the mean age at death of all significance, and even to falsify many conclusions drawn by $D_{r}$. Ogle's method, for very few women continue to follow the same occupation for the twenty years required, much less throughont their lives. Domestic servants, shop girls, and female clerks usually mary after a few years. Servants, c'specially, rarely die as such, and it is only as mill or factory hands that women to any great extent licep to the same work after marriage as before. I would not underrate the ill results of sedentary employment in overcrowded rooms, but I do believe that the very high mortality, especially from phthisis, among needlewomen, \&c., may be in large part explained by the removal through marriage of the healthier and comelier girls.

A very prevalent source of error in questions of this kind is the fallacy of ascribing to one particular cause, perhaps a real and powerful factor, but still only one among others not less powerful, the whole effect of a plurality of causes. The so-called "Temperance Advocates" are constantly appealing to 
the notoriously high mortality among tavern kcepers and their assistants as if it were wholly due to drink. But if shop attendants and work-women suffer from long hours and illrentilated rooms, the far longer hours spent in the fouler air of the bar, 'mid blazing gas-lights and an unwashed crowd, without even a weekly day of rest, cannot fail to have a worse effect on the health of these young persons even if they were total abstainers. In fact, while no one can doubt that publicans lead easier lives and are more given to indulgence in drink than barmaids and other tavern servants, the comparative mortalities of the two classes are calculated by Dr. Ogle as 1521 and 2205 respectively.

So, too, in determining, e.g., the influence of lieredity in the production of plithisis, of cancer or leprosy, or of a certain milk supply in the spreacl of a fever, much more than the mere concurrence or succession of two phenomena is required to prove their relation as cause and effect. In every such investigation the inductive methods of agreement, of clifference, and of concomitant variations must be worked through, and the possibility of a plurality of causes should not be lost sight of.

Phithisis may for statistical and public health purposes be considered synonymous with pulmonary tuberculosis, for though there are several forms of phthisis, as chronic catarrlial and interstitial pneumonias, and that caused by the inhalation of irritative dusts, the pneumoconiasis of Hirt, the subjects of these become as a rule sooner or later tuberculous, tubereulosis being an infective disease set up by the invasion of the lymphatic vessels and gliunds by bacilli gaining access thereto through a mucous surface, the seat of some pre-existent catarrh or morbid state depriving it of the resistive power possessed by healthy surfaces, on which they speedily perish or are destroyed by phagocytes. The predisposing catarrhs are prevented by drying of the soil and dwelling, and by improved conditions of living generally, and the risk of infection by the better ventilation of houses and workshops, and the intelligent disposal of the sputa. The mortality from phthisis has been reduced during the present generation by 30 to 40 per cent., but some persons maintain that this is by no means an unmixed good, for they say it involves the preservation and perpetuation of a feeble race prone to other diseases, especially those of the nervous system, which the former high mortality from phthisis tended to eliminate. This I believe to be a fallacy, for such a doctrine would be true only if phthisis killed its rictims before attaining the age of marriage, or incapacitated them from becoming the parents of families; whereas it does not in the majority of cases appear until they have reached that period of 
life, and are in a large proportion of instances already married, while phthisical persons are at least as prolific as others, and they continue to procreate or bear children until the last months of their lives. And I camnot but believe that the children of those who, however susceptible, have escaped infection and are in the enjoyment of fair liealth, perhaps of in other respects full mental and bodily vigour, are far less likely to grow up weakly and susceptible either to tuberculosis or to other forms of constitutional disease, than those whose parents were at the time of their birth already in more or less advanced stages of actual tubercular discase. "Wo know that even these children, if brought up amid the most favourable surroundings, may grow into robust men and women; and it surely seems reasonable to assume that the same conditions as those by which the parents were sared from succumbing to the tubercular infection to which they, as all of us, are constantly liable to be exposed, must tend to the raising of a less susceptible generation, from whose chiliten again the last taint of susceptibility, and of the feebleness that it inclicates, will be eliminated and lost, reversing the gloomy forecast of the Roman poet:

\section{“ Etas parentum, pejor avis, tulit \\ Nos nequior's, mox daturos \\ Progeniem vitiosiorem."}

All class mortalities, death-rates at certain ages and the like, must, as I have already insisted, be calculated on the population living at those ages or belonging to the particular class, but there are some of these in which the sonces of error and elements of uncertainty are sucl as to suggest the description of "indeterminate and impossible," represented respectively by those of armies and the case mortalities of hospitals. To throw together under the head of "foreign service" the mortalities of troops in Burma and in Canada and to compare the rates with those at home is obviously unfair. Besides no soldier can die on the roll of his regiment, save from violence, accident, or acute disease, unless through the neglect of the authorities to invalid him in time: and the only trustwortly indication of the sanitary condition of an army is the percentage of deaths and invaliding from all causes among men of like ages and periods of service. And if a corps or a station is to be compared, not with itself at a former time, but with others, their conditions must be as nearly as possible the same except in respect of that the influence of which, be it climate, quarters, age, or anything else, it is desired to determine.

In the case of hospitals, and to a less extent of prisons, the difficulties are well nigh insuperable. The mortality must be 
calculated not on the arerage strength, but on the number of admissions in the year. Thus, in a hospital having 100 beds, where the average period of treatment was six weeks, 100 deaths in the year would represent a mortality of, not 100 per cent., but of 100 in 800 , i.c., $12 \frac{1}{2}$ per cent. But the circumstances of hospitals as regards the nature and gravity of the cases, the proportion of medical to surgical beds, the demand for admissions, and consequent length of time during which a patient is allowed to remain are so diverse that comparisons are rarely possible. Such differences I believe fully explain the alleged urcater success, i.e., lower case mortality in small prorincial hospitals than in those of manufacturing and shipping towns as London, Liverpool, Birmingham and Glasgow, to say mothing of the reputation of the staff's attached to the latter which attracts grave cases from elsewhere.

The only legitimate comparisons are between those in which all conditions, save the one in question, are practically identical. Such perhaps would be maternity or ferer hospitals where patients suffering in similar manners are retained till recovery or death; the same hospital in successive years or periods, and hospitals of the same character, situated in the same locality and among the same population. In such cases the results of the practice or the rejection of serumtherapy or antiseptic methols, the adoption of the pavilion system or the retention of the solid block, or other striking contrast may fairly be accepted as the determinimt factor of markedly divergent mortalities.

The Cicarman (Prof. W. II. Corlield) said he was sure they would accord a hearty vote of thanks to Dr. Willoughby for his most interesting and important paper. It was a paper which could not be discussed from all points and in all its beirings, but he had no doubt that one wuuld talke up this portion and another that, so that they might have a good discussion. Dr. Willoughby's reference to demography reminded him that when the International Cungress of Ilygiene and Demograpliy resolved to hold its session in London, in 1 s. 1 , as acting secretary of that Congress, he could find no one who understood what the word demography meant. So he proposed to the Committee that they should call it the Congress of Hilygiene and Statistics. But when the circulars were sent out with this title, such a hubbub was raised by the continental demographers, that the Committee had to alter the designation immediately. They reverted to the old title, but he had to put in the prospectus an explanation of the meaning of the word for the benefit of the English people, for the word was then practically unknown. He accordingly wrote to the leading dewographers on the continent, asking each one for a definition of "Demography." Every one answred the letter, but" 
not one sent a definition. So he put in the circular that "Demography is the science which studies the social conditions of communities from statistical points of view." That was translated into three other languages and sent abroad, and, as no one complained of it, he presumed it met all the different riews. It was a somewhat curious thing, but in 1879 he read a paper before the Congress of the Institute at Croydon on "Sanitary Fallacies," and now he was presiding at the reading of a paper on a lindred subject; they would, if they referred to that paper, see that he had given a few instances of statistical fallacies, and one had been, to a certain extent, alluded to by Dr. Willoughby, viz., that it was pointed out by Dr. Farr, a good many years ago, that the influence of immigration on the death-rate of a population was nothing like so great as was frequently made out. If you added the deaths of immigrants to the deaths in any community, you ought to increase the population by a reasonable amount, due not merely to the immigrants themselves, but to the other children who had been born at the same time and who hiad died before the age of the immigrants. He had been very much interested with Dr. Willonghby's remarlss as to domestic servants being " immortal." That was a most bappy illustration, and be was very thankful to him for it. It was perfectly true in the way Dr. Willoughby put it. In his own district he had very curious instances of it. St. George's, Hanover Square, used to be divided into three sub-postal districts, Mayfiar, Hanover Square, and Belgravia. He used to calculate out what he called the mean length of life-not by the life table method, but by Dr. Bristowe's formula-and that for Mayfair was generally between 90 and 100 ; but when it came to between 100 and 105 as the mean duration of life for the population of Mayfair, he had to drop it. This result was due entirely to the "immortals." Since that time the Registrar-General had combined Mayfair and Hanover Square, so that he could revert to bis former proceeding without the results looking so ridiculous as they wonld have done otherwise.

Mr. Nows Huxmmers (London) remarked that the paper, which was a useful one, and one which Medical Officers of Health who had to study the incidence of rital statistics, would appreciate, stated a number of obrious and uncontrorertible facts which scarcely admitted of discussion. In the first place Dr. Willoughby's paper ought to lead people to adopt greater precision in the use of terms, especially the term death-rate, which was very frequently used in an incorrect and misleading manner with regard to statisties, and he thought the Institute might do usefinl work in calling attention to this. Passing to the more general suljject, Mr. Humplireys said that he was sure that all Medical Officess of Health would admit that the crux of the difficulty with which they had to contend was the estimate of the population. With regard to that subject, hat thouglit the Sanitary Institute, as the period when another census would be taken up was approaching, might possibly aid sanitary science and public health generally by using its influence to impress upon the Government the absolute necessity, if health statistics are to have the value and utility- 
they ought to have, of instituting a quinquemnial census. The London census in 1596 was the first eximple of a quinquennial census in England. It was brouglit about accidentally under the Equalisation of Rates Act. That Act combined two very important improvements in census taking, it provided an intermediate census, and it also imposed upon the local sinitary authorities the obligation to furnish annually the number of inhabited houses on the Rate books within each district. The latter information is of the greatest ralue in revising the estimates of population in intercensal periods, and he much hoped that the Sinitary Institute would use its influence in promoting in census Act, which would provide for a quinquennial census and an annual return of inhabited houses from each sanitary authority throughout the country. The only other matter he would refer to was one which he thought Medical Otticers of l [ealth would admit, was of great importance, namely, the question of areals. When registration was estiblished sixty years ago, the Poor Liw Union was necessarily made the unit for registration purposes. Unfortunately the Registration Act compelled the continued use of that unit, which liad many obvious objections. But fortunately there were signs now of a great desire throughout the country to assimilate registrition areas with the Poor Law areas, and to alter the registration districts wherever possible, so that they could be made to anree with the sinitary districts themselves. These points were, in bis opinion, of the first importance to sinitary statistics, and he hoped the Sinitary Institute would see its way to support improvements in this direction.

Dr. E. W. Hupe (Liverpool) said that Dr. Willoughby's paper was to him most interesting and retreshing. The new ways in which he had presented old fincts, and the many new considerations he laad given, afforded for them something to curry away and think about. He said, statisties might be made to prove anything, so might words. If people put words to wrong uses that was no reason why the use of words should be discredited, so with vital statistics. He did not propose to follow Dr. Willoughby through the intricacies of his interesting paper, but he did wish to draw attention to one or two points which were alluded to in it. One of these had already been referred to by Mr. Humphreys, and it was certainly one which most concerned Meclical Olficers of Health, viz., the necessity for an accurate basis. The whole of their subject bristled with possible fallacies, and therefore it became the more essential that the groundwork or bissis of their calculations should be correct. Now, they had every reason at the present time to believe that their basis was incorrect. He spolie with deference in the presence of such eminent statisticians as Mr. Noel Humphreys, but he thought that that gentleman would agree with him that the probability is that the Registrar General did not estimate one single large town correctly. Week after week it was carefully set forth in the newspapers that the death-rate of this place is so much, and the death-rate of that place something else. 'The places were all strung together without 
comment for comparison, and when enquiries were made as to the basis of the calculations contidence was rudely shaken. Those most (qualified to judge did not consider that the basis of those calculations at all approached accuracy. He had written to the Medical Officers of Health of most of the large towns, asling (1) whether or not they considered their population was estimated correctly, and (2) that if they considered the estimate was incorrect, did they consider the error great enough to ritinte the returns which were published by the Registrar General? Some of the replies were as follows: Birmingham, the returns are incorrect by many thousands; Newcastle, West Ham, MIanchester, salford, all considered the returns incorrect, and that the weekly returns are erroneous; Brighton and Nottiugham are doubtful, although they addod that the system is unsatisfactory: Hull, not correct according to the opinion of the Medical Officer of Health ; Bradtord, not correct; Gateshead, Derby, Huddersfield, Blacliburn, Norwich, Plymouth, and Sunderland, all said that the error is great enough to vitiate the returns which were published weelily by the Registrar Genemal. Other towns were Oldlam, not correct; Halifax, doubtfu]; Burnley is not satisfied as to the Registrur General's returus, and had long since fallen back upon maling its own estimate; sheflield considered that the error is between 31$), 000$ and 10,000 ; Portsmouth had a sinilar opinion, while Wolverhampton and Birkenhead also expressed the view that the Registrar Genelal's estimate is incorrect. It would be seen that most of the large towns were included in that list. Now, with regard to Liverpool, which had been referred to by Dr. Willoughby, he should lilie to say that at the last census the Registrar Generulis estimate of the population of that eity was 100,000 in error. It seemed almost incredible that year after year so egregious and gross an error could have gone on without some investigation or check. But what is the position to-day? The population of Liverpool is estimated by the Registrar General to be 0333,000 , and the increase since the last census is estimated to be 4,200 . On making a special census of the inhabited houses by qualified porsuns, acting under special instructions-each one of the 400 persons employed having a book with instructions as to how to take the number of empty houses there were in each street-it was found that there were upwards of 13,000 inhabited houses more than there were in the last census. Surely that conflicted with the Registrar General's estimate that there were only 4,000 more people in Liverpool; if there were 13,000 inhabited houses where did the people who lived in them come from? Again, they found that the number of registered roter's since the last census, including the extended area, had increased by 26,000. Now, voters could not put their own names on the lists, very few of them presumably could be bogus voters, for claims were closely criticised before the revising barrister by the opposing political agents. Those 26,000 roters did not exist in the imagination. These seemed to bim strong grounds for asling the Registrar General to consider the desirability of revising lis estimate of the population of Liverpool, but he had not seen bis way to act upon the suggestion. Naturally 
the question was a thorny one, as had been pointed out on his behalf; for if it were done for one town it would have to be done for another. But what was to be particularly complained of was the publication every week, in an oflicial form, with the weight and authority of a Government Department, of statistics, which in all probalbility were not only inaccurate, but which were grossly inaccurate and misleading. It miglit be aslied, what does it matter whether they are right or whether they are wrong? It mattered a great deal. For one of the means by which sanitary progress could be gauged was the reduction, or otherwise, in the deat $]_{1-r a t e}$ and the rate of ,ickness. A district was found to be notoriously unbealthy, the unlealthy areas were remored, wille streets were constructed, wordinen's dwellings of the most approved style erected at enormous cost, prorision wais made for the infective sick, the water-supply was improved, scavenging increased, and what was the result? The death-rate was going up by leaps and bounds accorling to the Registral General. Now il Councillor who took an interest in lis city naturally looked for some reward for his pains and for the public money speut, and it certainly was discouraging to find this apparently anomalous result. Some persons perhaps are not actuated with the desire to advance the public good, and they were only too glad to have an occasion to turn round and say sanitarians were wrong, and point to the Registrar General's returas, which they say would not be published unless they were correct, for he had means at his clisposal which the local oflicers have not. Well, he rentured to think that these matters were not properly considered, and that the lasis needed revision, and he would libe to go a step further than $\mathrm{M} \mathrm{Hr}$. Humphreys, with regard to the means by whicll the Sanitary Institute could advance the object they lad in view, and that was to propose a resolution to the effect that in the opinion of that meeting a more frequent census is necessary. He failed to see that anything but good could result from that. In Germany the census was quinquennial, and in Holland he believed that it was still more frepuent, though he did not know what it was in France and ot her countries. But in olapan a most careful method was adopted, which meant practically that an ammual census was taken. Japan had taken the lead in many matter's, and it laal certainly taken the lead in this. In fixing upon this one point which so nearly concerned Medical Officer's of lilealth, he should not like to be understood to have a less apprecintion of other important points that Dr. Willoughby had carefully brought out. All who had listened to him, especially those who hiad giren some previous attention to the subject, would benefit by his paper'; meanwlite, if in order, he should like to move "That in the opinion of this sersional Meeting of the Member's of The Sanitary Institute, it is desirable that a quinquennial census enumeration of the population of the whole country should be taken, in order to ensure greater accuracy in statistics relating to the public health."

Mr. Nore Huapuners (London) said be should like very heartily to second Dr. Hope's proposition. It should, however, be remembered 
that the Registrar General really made no estimate of populations, he did not pretend to do so; it was quite out of his power to make an estimate of a locil population. In all his returns it was stated clearly that "if the population has increased during the current decade as it increased during the preceding clecade," that the population would be so muck, and if the population is so much, that the rleath-rate would be so much. During the decade 18\$1-90, an attempt was made to get from the municipal authorities of many large towns, information as to the number of inbabited houses on the rate-books. That application was made to the Town Council of Liverpoul, and they retulised to give any assistance on the matter, apparently beciuse the usual hypothesis was obviously overstating the population and understating the death-rate. The Registral General was thus baffled in his attempt to get the assistance of the local authority at that time, consequently the result at the end of the period was the excessive population to which Dr. Hope had called attention. Tn seconding the proposition, he should like to add to it as an addendum, "and that, at the same time, the Act should specify that every local authority slall furnish to the Registrar General the number of inhabited houses on the rate-books annually." If that information were given the Registrar General would have some basis upon which to revise the population, and really to estimate the population of a town. Without that information they would have to trust to a quinquennial census, and even five years was too long for calculating the population of towns of rapid growth.

Dr. Hope's motion wals then agreed to nem. con.

Mr. Noen Humpinzers moved, and Dr. Bond seconded, "That in the opinion of this Sessional Meeting of the Members of The Sanitaly Institute, in the Census Act provision should be made for anl annual return of inhabited houses on the late-books, by the municipal authorities of towns."

This was agreed to nem. con., and it was further resolved to request the Council of the Institute to bring the resolutions before the Gorernment in such way as they may think fit.

Dr. W. A. Boxn (London) salid that he would mention one point in regard to deaths in outlying public institutions. As a metropolitan Medical Oflicer of Health, he found there wats a number of persons who after having been only a short time in the district rent to workhouses, infirmiries, or hospitals, and their deaths were returned as belonging to that district. He thought there ought to be some limit of time in regard to which such deaths should be included in the local returns.

Dr. Srarons (M.O.H., Bath) said he should like to ask Dr. Willoughby if he could suggest any means of correcting for the proportion of the "immortals." In Bith, with a population of 52,000 , they had 600 servants, probably a larger proportion of servants than any other large town; and he quite agreed with $\mathrm{Dr}$. 
Willoughby as to their influence on vital statistics, this influence ought to be allowed for if possible. With regard to the census, he should like to know if information concerning the house or street population was kept. In Scotland, he had been informed, particulars concerning each street could be obtained by the local authority it the time the census was taken.

Mr. A. S. E. Ackerarars (London) remarled with regard to the statement, " statistics may be made to prove anything," that it ought to read "statistics may apparently be made to prove anything;" because figures cannot alter facts, and if statistics were frandulently manipulated they did not prove anything. Dr. Willoughby's remarks with regard to the unbealthiness of occupations reminded him of the argument often used by anti-teetotalle's, who were so fond of pointing to the great ages attained by their grandfathers, ignoring the rast majority who died oft, leaving the few pinacles to whicli they so proudly point. Something similar occurred later on in the paper, when Dr. Willough by referred to the arguments of temperance advocates, based on the high rate of mortality among tavern keepers and their assistants. But although the tavern proprietor could not be said to be over-worked, yet he was extremely well clothed and fed, and was not exposed to other unhealthy occupations, as were many total abstainers, yet the death-rate among tavern lieepers was excessive high. In the "United Kingdom Temperance and General Providence Institution," the deaths in the temperance section only realised 70 per cent. of the expected deaths, whereas 95 per cent. of the expected deaths actually occurred in the general section, which was composed of strictly so-called moderate drinkers, hotel keepers and their servants, and were not insured by this institution at all.

Dr. E. F. WILLOdGinz, in acknowledgment expressed his gratification with the whole tone of the discussion, and his appreciation of Mr. Noel Humphreys' criticisms. Many of Dr. ILope's remarks reminded bim of Jobu Stuart Mill's amusing description of the way in which we, so soon as a want was felt sufficiently urgent to call for legislation, created a new aluthority, with a new district, with a new constituency and suffiage, with new rating powers and a new staff of officials until the conflict and overlapping of the several authorities resulted in a state of administrative chloos. He feared that be could not help Dr. Symons, except by suggestiug that at the next census he should obtain copies of the enumerators' tables, and having ascertained the number and ages of all domestic servants, born elsewhere than in Bath, and the percentage that such persons bore to the total number living in each age period, he could make a corresponding deduction from all subsequent estimates of the population. The death-rate thus obtilined would be very instructive, though it would not receive official recognition. 